Editorial

\title{
Vantagens e desvantagens do uso de software na análise de dados qualitativos
}

\section{Advantages and disadvantages of using software for qualitative data analysis}

\author{
António Pedro Costa ${ }^{1}$, Luís Paulo Reis ${ }^{2}$ \\ pcosta@ludomedia.pt, lpreis@dsi.uminho.pt \\ ${ }^{1}$ CIDTFF/UA - Centro de Investigação Didática e Tecnologia na Formação de Formadores, \\ DEP/UA - Departamento de Educação e Psicologia, Universidade de Aveiro, Aveiro, Portugal \\ ${ }^{2}$ EEUM/DSI - Escola de Engenharia da Universidade do Minho, Departamento de Sistemas de \\ Informação, LIACC - Laboratório de Inteligência Artificial e Ciência de Computadores, Portugal
}

DOI: 10.17013/risti.23.0

\section{Introdução}

A utilização de pacotes de software na análise de dados qualitativos é uma realidade que poucos investigadores conseguem, atualmente, contornar. Alguns investigadores recorrem a soluções não específicas, tais como o Excel ou o Word para a análise dos seus dados qualitativos. Outros, têm a necessidade de indicarem nas suas publicações que exploraram determinada ferramenta de análise de dados, sem a terem efetivamente usado. Independentemente do caminho que o investigador segue, é claro que o uso correto de ferramentas específicas para a análise de dados qualitativos credibiliza o projeto de investigação. A comunidade acredita que tal como na utilização de um processador de texto para a escrita de texto, são inúmeras as vantagens no uso destas ferramentas na análise de dados: a) permitem a análise de uma enorme quantidade de dados; b) incluem procedimentos de contextualização e de validação; c) permitem a definição de categorias de forma indutiva e dedutiva, codificação e recodificação, exploração e cruzamento de diferentes formatos de dados (texto, imagem, áudio e vídeo); d) permitem visualizações avançadas dos dados; entre muitas outras (Spannagel, Glaser-Zukuda, \& Schroeder, 2005; Lage \& Godoy, 2008; Costa, 2016). Identificamse estas características como possíveis vantagens da utilização deste tipo de software. 
Como refere Evers, Silver, Mruck, \& Peeters (2011) não existe o melhor software. Cada pacote de software tem as suas vantagens e desvantagens, e por esse motivo não existe um software melhor do que todos os outros em todos as suas funcionalidades para análise qualitativa. Por conseguinte, é compreensível que os investigadores muitas vezes tenham dificuldade em decidir qual o pacote em que investem tempo e esforço na sua aprendizagem. Por outro lado, Costa, Souza \& Souza (2016) no capítulo "Trabalho Colaborativo na Investigação Qualitativa através das Tecnologias" realizaram um estudo aos participantes do Congresso Ibero-Americano em Investigação Qualitativa (www.ciaiq.org) com intuito de identificarem quais os critérios para a seleção de um software de análise qualitativa. Foi utilizada uma escala de Likert com cinco níveis e 14 critérios pré-definidos. Nas suas respostas, os 362 participantes inquiridos deram mais importância, ou seja, responderam como "Muito Relevante" aos seguintes critérios: "Adequabilidade ao tipo de investigação" (262 respostas), "Adequabilidade ao desenho de investigação" (233 respostas), "Funcionalidades" (230 respostas) e "Usabilidade do software" (223 respostas). Com 200 respostas, os participantes referiram a "Disponibilidade do software na instituição".

Elencar as desvantagens no uso destas ferramentas é algo que acompanhou o surgimento destes pacotes de software. Brent (1984) na década de 1980 já mencionava como desvantagem as competências computacionais que os investigadores teriam que adquirir. Gibbs, Friese, \& Mangabeira (2002) afirma que o software é menos útil para abordar questões de validade e confiabilidade nas ideias temáticas que emergem durante a análise de dados. Ryan (2009) concluiu que "os pacotes de software permitem aos investigadores tornar visíveis os processos metodológicos de um estudo e como tal, deste modo, torná-lo mais confiável” (p. 158). Davis \& Meyer (2009) sugeriram que é essencial que o investigador aprenda a explorar o software antes de usá-lo no projeto, e que não se pode separar o investigador do programa. O investigador decide quais as características e as potencialidades a utilizar e quando e onde as utilizar. Por outro lado, existe uma série de críticas que são colocadas ao uso de software na análise de dados qualitativos: a) possibilidade de perder o controlo no processo de codificação; b) confundir a software com a metodologia; c) encorajamento de estruturas de codificação complexas e detalhadas resultando num excesso de codificação; d) aumento desnecessário da quantidade de dados recolhidos, levando ao risco do comprometimento da análise em profundidade; e) impossibilidade de comunicação entre sistemas (pacotes de software); f) levam os investigadores a utilizar um método particular de análise, de acordo com as características da ferramenta (Lage \& Godoy, 2008).

Concluímos com uma citação de Brent (1984) que, passadas 3 décadas, continua válida e atual: "A análise de dados qualitativos implica uma série de tarefas aborrecidas e demoradas, das quais a maioria dos investigadores gostaria de escapar. Mesmo o investigador qualitativo mais consciente rapidamente começa a pensar que tais tarefas não são um uso económico do seu tempo. No entanto, essas tarefas exigem fundamentos teóricos sustentados e, portanto, são difíceis, se não impossíveis, de delegar a terceiros" (p. 37) e são também impossíveis de delegar a um pacote de software.

Este número especial da RISTI - Revista Ibérica de Sistemas e Tecnologias de Informação contém oito artigos selecionados pela comissão organizadora e científica do $6^{\circ}$ Congresso Ibero-Americano em Investigação Qualitativa (CIAIQ2017), de entre os 
melhores trabalhos de investigação da conferência relacionados com as temáticas dos Sistemas e Tecnologias da Informação. Os artigos deste número especial da RISTI foram estendidos e aprofundados em relação às versões publicadas nas atas do CIAIQ2017.

O CIAIQ2017 decorreu de 12 a 14 de julho de 2017 em Salamanca, Espanha. O congresso recebeu um total de 667 submissões de artigos, envolvendo autores de 29 países. Cada artigo foi submetido a um processo de revisão double-blind por uma comissão científica composta por elementos altamente qualificados nas áreas científicas do congresso.

Esta edição especial da RISTI é composta por artigos que se basearam em metodologias qualitativas como ferramentas para esta articulação e inovação.

\section{Estrutura}

O primeiro artigo analisa as motivações do uso de um aplicativo social (Solidarius) para a realização de doações para famílias carente. Os autores concluiram que a solidariedade mediada pela tecnologia, possibilita a existência de um vínculo, que permite ao utilizador um sentido de pertença a uma instituição ou a uma causa maior do que ele mesmo, além de gerar os sentimentos de satisfação e gratidão.

O segundo artigo descreve uma investigação experimental onde, fazendo uso da classe inversa, detecta as deficiências dos materiais educativos empregados na docencia universitaria para a sua melhoria. Foram aplicados questionários para obter a informação dos alunos. A investigação mista foi usada para a deteção dos materiais e melhorar os efeitos da sua aplicação.

O terceiro artigo destaca a validação de um questionário de satisfação para poder medir o impacto da introdução da gamificação no ensino superior. Foi usado o software webQDA para realizar a análise qualitativa das respostas e comentários emitidos pelos peritos, possibilitando a introdução de novas perguntas e alterações/melhorias às perguntas iniciais, com o objetivo de se conseguir validar o questionário de satisfação.

O quarto artigo aborda gestão inadequada de Resíduos de Serviços de Saúde (RSS). Apoiado em técnicas de pesquisa qualitativa. Avaliou-se o funcionamento de um hospital através de aplicação de entrevistas aos stakeholders, aos funcionários e ao pessoal operacional. Também foi realizada uma observação diária das atividades. Os resultados permitiram concluir que a gestão de RSS tem algumas deficiências o que eleva consideravelmente o potencial risco dos resíduos dos serviços de saúde ao meio ambiente e à saúde pública.

$\mathrm{O}$ artigo seguinte pretende dar resposta ao problema do abandono escolar através de um projeto implementado fora do horário escolar. Para uma maior compreensão e profundidade das dimensões a estudar, foi usada uma abordagem qualitativa. Para obter os dados, foi aplicado um questionário semi-estruturado no qual responderam 170 alunos. Os resultados indicam a multiplicidade de fatores de risco no absentismo e abandono que exigem intervenções igualmente múltiplas de diferentes administrações e instituições.

O sexto artigo apresenta dois protocolos de pesquisa propostos para identificar o grau de influência das informações ambientais sobre o processo criativo de designers, 
empregando-se métodos qualitativos. Foram realizados testes pilotos de aplicação dos protocolos, sendo reformulados validando a aplicabilidade dos instrumentos.

O sétimo artigo avaliou a usabilidade do site do Instituto Nacional de Educação de Surdos, a partir da abordagem centrada em consumidores. Das Heuristicas de Nielsen, o site atendeu plenamente a seis e parcialmente a duas, não tendo atendendo no entanto a uma delas. A qualificação da usabilidade do site do INES foi qualificada como boa, considerando a escala de pontuação proposta pela própria Ficha de Avaliação.

Finalmente, o último artigo apresenta o caso do Simulador de Operações Cibernéticas (SIMOC) adotado pelo Exército Brasileiro no treinamento de pessoal em defesa cibernética, sob a perspectiva da gamificação. Os autores estudaram a ocorrência de onze elementos de jogos e de outras práticas associadas à gamificação. Foram analisados documentos e realizadas entrevistas aos membros da equipa que trabalha com o SIMOC e com alunos que participaram em formações com o uso do simulador.

\section{Agradecimentos}

Os editores gostariam de agradecer a todos os que de forma direta ou indireta colaboraram com o sucesso do CIAIQ2017 e com a produção deste número especial, incluindo os participantes, autores, comissão organizadora e comissão científica, apoios, equipa editorial, entre muitos outros. Através do seu interesse, participação e da qualidade e rigor do seu trabalho científico, agora publicado na RISTI, esperamos que possa ser promovida a expansão da investigação qualitativa numa área tão relevante como é a dos Sistemas e Tecnologias de Informação.

\section{Referências}

Brent, E. (1984). Qualitative computing: Approaches and issues. Qualitative Sociology, 7(1-2), 34-60. http://doi.org/10.1007/BFo0987106

Costa, A. P. (2016). Cloud Computing em Investigação Qualitativa: Investigação Colaborativa através do software webQDA. Fronteiras: Journal of Social, Technological and Environmental Science, 5(2), 153-161. http://doi. org/10.21664/2238-8869.2016v5i2.p153-161

Costa, A. P., Souza, D. N. de, \& Souza, F. N. de. (2016). Trabalho Colaborativo na Investigação Qualitativa através das Tecnologias. In D. N. de Souza, A. P. Costa, \& F. N. de Souza (Eds.), Investigação Qualitativa: Inovação, Dilemas e Desafios (1a, pp. 105-127). Oliveira de Azeméis - Aveiro: Ludomedia.

Davis, N. W., \& Meyer, B. B. (2009). Qualitative Data Analysis: A Procedural Comparison. Journal of Applied Sport Psychology, 21(1), 116-124. http://doi. org/10.1080/10413200802575700

Evers, J. C., Silver, C., Mruck, K., \& Peeters, B. (2011). Introduction to the KWALON Experiment: Discussions on Qualitative Data Analysis Software by Developers and Users. Forum: Qualitative Social Research, 12(1). 
Gibbs, G. R., Friese, S., \& Mangabeira, W. C. (2002). The Use of New Technology in Qualitative Research. Introduction to Issue 3(2) of FQS. Forum Qualitative Sozialforschung / Forum: Qualitative Social Research; Vol 3, No 2 (2002): Using Technology in the Qualitative Research Process, 3(2). Retrieved from http://www. qualitative-research.net/index.php/fqs/article/view/847

Lage, M. C., \& Godoy, A. S. (2008). O uso do computador na análise de dados qualitativos: questões emergentes. RAM. Revista de Administração Mackenzie, 9(4), 75-98. http://doi.org/10.1590/S1678-69712008000400006

Ryan, M. (2009). Making visible the coding process: Using qualitative data software in a post-structural study. Issues in Educational Research, 19(2), 142-161.

Spannagel, C., Glaser-Zukuda, M., \& Schroeder, U. (2005). Application of Qualitative Content Analysis in User-Program Interaction Research. Forum Qualitative Sozialforschung/Forum: Qualitative Social Research, 6(2). 